Elisângela Bastos de Mélo Espíndola, Jairo José Ribeiro Toscano de Brito Júnior e Rayssa de Moraes da Silva

Recursos para o Ensino de Volume em Níveis de Atividade do Professor de Matemática

\title{
RECURSOS PARA O ENSINO DE VOLUME EM NÍVEIS DE ATIVIDADE DO PROFESSOR DE MATEMÁTICA
}

\section{RESOURCES FOR TEACHING VOLUME AT A MATH TEACHER'S ACTIVITY LEVELS}

\author{
Elisângela Bastos de Mélo Espíndola ${ }^{1}$ \\ Universidade Federal Rural de Pernambuco \\ Jairo José Ribeiro Toscano de Brito Júnior ${ }^{2}$ \\ Universidade Federal Rural de Pernambuco \\ Rayssa de Moraes da Silva ${ }^{3}$ \\ Universidade Federal Rural de Pernambuco
}

\section{Resumo}

Este estudo objetivou identificar o sistema de recursos de um professor de matemática nos níveis de sua atividade e na sua relação com o ensino de Volume de Sólidos Geométricos. Tomou-se como bases teóricas a abordagem documental do didático (GUEUDET; TROUCHE, 2007), o modelo de níveis de atividade do professor (MARGOLINAS, 2002) e o seu vínculo com os recursos no trabalho do professorexterno à sala de aula (MARGOLINAS; WOZNIAK, 2010; SABRA, 2016). Trata-se de um estudo de caso com um professor de matemática em uma turma do $2^{\circ}$ ano do Ensino Médio. Tomando-se por referência a investigação reflexiva (GUEUDET; TROUCHE, 2010), durante a fase de coleta de dados, buscamos acompanhar as atividades do professor em um período significativo de tempo, de modo contínuo e sobre o princípio reflexivo das informações, pelo pesquisado e pelo pesquisador. Os instrumentos de coleta de dados foram: a trajetória documental, a representação esquemática do sistema de recursos e entrevistas. Dentre os resultados, destacam-se a interação entre a trajetória documental e o sistema de recursos do professor (no nível +3 - valores e concepções sobre o ensino/aprendizagem e nível +2 - construção global do tema) e as escolhas do professor para um projeto de aula (nível +1 ) sobre Volume de Sólidos Geométricos. Ademais, distingue-se o que o professor utilizou e mobilizou para preparar o ensino do tema (recursos - mãe) do que o professor produziu e desenvolveu a partir dos recursos de origem (recurso - filho) (HAMMOUD, 2012). Nesse caso, faz-se uma análise de uma ficha de exercícios selecionada da internet e as adaptações realizadas pelo professor, prevendo seu uso em sala de aula.

Palavras-chave: Abordagem documental do didático; Níveis de atividade do professor; Volume de sólidos geométricos.

\footnotetext{
Abstract

1 ebmespindola@gmail.com

2 jairo.tosc@gmail.com

3 rayssasmoraes@ hotmail.com
} 
Elisângela Bastos de Mélo Espíndola, Jairo José Ribeiro Toscano de Brito Júnior e Rayssa de Moraes da Silva

Recursos para o Ensino de Volume em Níveis de Atividade do Professor de Matemática

The objective of this work was to identify the resource system of a mathematics teacher at the levels of her/his activity and her/his relationship with the teaching of Volume of Geometric Solids. The documentary approach to teaching (GUEUDET; TROUCHE, 2007), the model of teacher activity levels (MARGOLINAS, 2002) and her/his relationship with resources in the work of the teacher outside the classroom were taken as theoretical bases (MARGOLINAS; WOZNIAK, 2010; SABRA, 2016). This is a case study with a mathematics teacher in a class of high-school 2nd graders. Taking into account the reflexive research (GUEUDET; TROUCHE, 2010), during the data collection phase we sought to follow the teacher's activities in a significant period of time, on a continuous basis and on the reflective principle of the information, by the researched and the researcher. The instruments of data collection used were the documentary trajectory, the schematic representation of the resource system and interviews. Among the results, we highlight the interaction between the documentary trajectory and the teacher's resources system (at the +3 level - teaching/learning values and concepts and the +2 level - global construction of the theme) and the teacher's choices for a lesson plan (level +1 ) on Volume of Geometric Solids. In addition, it is distinguished what the teacher used and mobilized to prepare the teaching of the theme (mother resources) of what the teacher produced and developed from the original resource (daughter resource) (HAMMOUD, 2012). In this case, we analyze an exercise sheet selected from the internet and the adaptations made by the teacher, predicting their use in the classroom.

Key words: Documentary approach of didactic; Teacher's levels of activity; Volume of geometric solids.

\section{Introdução}

Apresentamos um estudo sobre o sistema de recursos de um professor de matemática nos níveis de sua atividade e na sua relação com o ensino de Volume de Sólidos Geométricos, desenvolvido na disciplina de Estágio Supervisionado Obrigatório (ESO) do curso de Licenciatura em Matemática da Universidade Federal Rural de Pernambuco - cujas questões norteadoras foram: Como se configuram os recursos nos diferentes níveis de atividade do professor? De que maneira a escolha de um recurso na preparação de uma aula se inscreve no sistema de recursos dos demais níveis de sua atividade? Tais questões surgiram da inquietação de, por vezes, serem realizadas observações de classe no ESO, sem que tenhamos uma compreensão da origem dos recursos utilizados pelos professores de matemática na preparação e implementação de suas aulas em classe.

Tomamos como referência teórica a abordagem documental do didático que trata o sistema de recursos de um professor, como uma entidade viva e estruturada em relação a sua atividade (de acordo com os níveis de ensino, os tipos de atividades...) 
Elisângela Bastos de Mélo Espíndola, Jairo José Ribeiro Toscano de Brito Júnior e Rayssa de Moraes da Silva

Recursos para o Ensino de Volume em Níveis de Atividade do Professor de Matemática

(GUEUDET; TROUCHE, 2007; 2010). Dessa forma, ampliamos o embasamento do presente estudo, utilizando-nos também do modelo de níveis de atividade do professor (MARGOLINAS, 2005) que põe em relevo, dentre outros aspectos, as atividades do professor-externas e internas à sala de aula.

A seguir expomos, de forma mais detalhada, algumas considerações sobre o quadro teórico adotado, antes da explicitação da metodologia ancorada na investigação reflexiva (GUEUDET; TROUCHE, 2010) e os principais resultados do estudo, para enfim apresentarmos algumas conclusões e perspectivas de novas pesquisas.

\section{A abordagem documental do didático}

A abordagem documental do didático (ADD) (GUEUDET; TROUCHE, 2007) distingue um recurso, considerado como todo elemento suscetível de auxiliar a atividade do professor (ex.: uma atividade transmitida por um colega, livros didáticos etc.), de um documento, o que o professor cria a partir deste recurso ou de um conjunto de recursos. Inspirada na abordagem instrumental de Rabardel (1995), o processo de construção de documentos a partir de recursos disponíveis, chamado gênese documental, combina dois processos imbricados:

\footnotetext{
O processo de instrumentação (os recursos equipam o professor e influencia sua atividade, esse processo marca as evoluções das práticas e dos conhecimentos profissionais induzidos pelo trabalho sobre os recursos) e o processo de instrumentalização (o professor se apropria dos recursos. Ele os ajusta, adapta, enriquece e os reorganiza de acordo com seu objetivo de ensino; trata-se assim, do processo de transformação dos recursos no curso de sua apropriação) (HAMMOUD, 2012, p.43).
}

A ADD considera o trabalho do professor em sua unidade e continuidade, como um trabalho com/para os recursos que constituem a matéria de seu ensino. Conforme Trouche (2016, p. 7): “Alguns recursos já foram apropriados pelo professor, eles estão "já lá", eles constituem o que chamamos de seu sistema de recursos, outros recursos são constantemente integrados ou retrabalhados".

Ressaltamos que uma diferença singular entre as noções de recurso e de documento diz respeito ao fato que, "não podemos qualificar o que o professor concebe, para por em prática em sala de aula, como sendo um documento; visto que um documento se constrói no tempo e supõe regularidades na ação do professor" (HAMMOUD, 2012, p.46). Desta forma, faz-se necessário distinguir o que o professor 
Elisângela Bastos de Mélo Espíndola, Jairo José Ribeiro Toscano de Brito Júnior e Rayssa de Moraes da Silva

Recursos para o Ensino de Volume em Níveis de Atividade do Professor de Matemática

utiliza e mobiliza para preparar o ensino de um tema (recursos - mãe) do que o professor produz e desenvolve a partir dos recursos de origem (recursos - filho).

Designa-se assim, um recurso filho como "o resultado finalizado, em um dado momento, para ser posto em prática em sala de aula, o produto e o fruto dos recursosmãe" (HAMMOUD, 2012, p.46). Pois, ao longo do tempo, o professor tem acesso a diversos recursos. Contudo, certos recursos são a posteriori retomáveis pelo professor; enquanto outros, não os são necessariamente. Logo, nem sempre todos os tipos de recursos têm um efeito significativo sobre o sistema documental do professor.

\section{O modelo dos níveis de atividade do professor}

O modelo dos níveis de atividade do professor busca "explicar a interação complexa entre as diferentes situações que o professor experimenta, em diferentes níveis, na maioria das vezes simultaneamente" (MARGOLINAS; WOZNIAK, 2010, p. 236). Segundo Margolinas (2005, p. 11), o referido modelo consiste em cinco níveis:

\footnotetext{
Nível +3 - Valores e concepções sobre o ensino/aprendizagem - Projeto educativo: valores educativos, concepções de aprendizagem e de ensino.

Nível +2 - Construção do tema - Construção didática global na qual se inscreve a aula: noções a estudar e aprendizagem a realizar.

Nível +1 - Projeto de aula - Projeto didático específico sobre a aula observada: objetivos, planificação do trabalho.

Nível 0 - Situação didática - Realização da aula, interação com os alunos, tomada de decisões na ação.

Nível -1 - Observação da atividade dos alunos - Percepção da atividade dos alunos, regulação do trabalho destinado aos alunos.
}

De acordo com Comiti, Grenier e Margolinas (1995) uma caracterização dos conhecimentos do professor em relação aos diferentes níveis de sua atividade pode ser analisada em termos de: nível +3: conhecimentos sobre a noção matemática e a aprendizagem; nível +2: conhecimentos relativos à situação de ensino/aprendizagem; nível +1 : conhecimentos globais sobre os conhecimentos e as dificuldades habituais dos alunos a propósito da noção matemática em jogo; nível 0: conhecimentos que são interpretações e/ou representações dos erros dos alunos e suas causas; eles vão servir para as decisões "no calor da ação"; nível -1: conhecimentos que permitem distinguir, no trabalho dos alunos, os erros ou as dificuldades que relevam do saber a ensinar.

No presente estudo, vamos nos deter em por em destaque os conhecimentos relativos ao nível +1 , tendo em vista o aprofundamento da análise sobre um projeto de 
Elisângela Bastos de Mélo Espíndola, Jairo José Ribeiro Toscano de Brito Júnior e Rayssa de Moraes da Silva

Recursos para o Ensino de Volume em Níveis de Atividade do Professor de Matemática

aula (nível +1). No entanto, ressaltamos sobre os referidos níveis do modelo, que um nível não está isolado dos demais níveis. De fato, esse modelo não é um modelo temporal, no sentido de que os níveis não seguem a ordem de numeração (LIMA; TRGAlOVA, 2008), mas interagem uns com os outros. Por exemplo, segundo Margolinas (2005), quando um professor planeja sua aula (nível +1), ele interage ao mesmo tempo com o que ele crê ser possível realizar em sala de aula (nível 0); de modo coerente a sua construção global do tema (nível +2), ou de suas concepções de ensinoaprendizagem (nível +3). Ou seja, o projeto de aula que vai ser construído está condicionado às escolhas operadas no nível da construção do tema, e enfim à situação didática a ser vivenciada; esta por sua vez, é largamente determinada pelas escolhas precedentes.

Por fim, ressaltamos as considerações de Margolinas e Wozniak (2010) e Sabra (2016), sobre o fato que os recursos à disposição do professor podem determinar a natureza das interações entre os níveis de sua atividade. De forma que os níveis de atividade do professor permitem levantar e analisar momentos precisos de sua documentação, que se inscrevem em uma gênese de articulação de atividades em sala de aula e fora dela. Nessa direção, apresentamos a seguir a metodologia adotada para o presente estudo, onde ensejamos estudar o sistema de recursos de um professor de matemática; em particular, nos níveis $+3 ;+2$ e +1 .

\section{Metodologia}

Para o desenvolvimento deste estudo de caso, adotamos a metodologia de investigação reflexiva (GUEUDET; TROUCHE, 2010), desenvolvida no seio da ADD, seguindo um dos seus princípios que é o acompanhamento da atividade docente durante um período significativo de tempo. Assim, durante um mês, empreendeu-se o estudo do trabalho documental de um professor de matemática do $2^{\circ}$ ano do Ensino Médio, precisamente para o ensino de Volume de Sólidos Geométricos (tema do momento, trabalhado pelo professor no $2^{\circ}$ bimestre).

Esse estudo ocorreu em uma Escola de Referência em Ensino Médio (EREM), situada em Recife - PE, de modo contínuo e sobre o princípio reflexivo das informações, durante a fase de coleta de dados (GUEUDET; TROUCHE, 2010). A fim 
Elisângela Bastos de Mélo Espíndola, Jairo José Ribeiro Toscano de Brito Júnior e Rayssa de Moraes da Silva

Recursos para o Ensino de Volume em Níveis de Atividade do Professor de Matemática

de serem identificados os recursos utilizados pelo professor em diferentes níveis de sua atividade, empregamos os seguintes instrumentos:

Quadro 1 - Instrumentos utilizados na coleta de dados para a identificação dos recursos nos níveis $+3,+2$ e +1

\begin{tabular}{|l|l|l|}
\hline Níveis & \multicolumn{1}{|c|}{ Identificação dos recursos } & \multicolumn{1}{c|}{ Instrumentos } \\
\hline $\mathrm{N}+3$ & $\begin{array}{l}\text { Recursos utilizados pelo professor para o } \\
\text { ensino e aprendizagem de matemática. }\end{array}$ & $\begin{array}{l}\text { Trajetória documental } \\
\text { Entrevista 1 }\end{array}$ \\
\hline $\mathrm{N}+2$ & $\begin{array}{l}\text { Recursos utilizados pelo professor para a } \\
\text { construção do tema Volume de Sólidos } \\
\text { Geométricos. }\end{array}$ & $\begin{array}{l}\text { Representação esquemática do } \\
\text { sistema de recursos (RESR) } \\
\text { Diário de bordo } \\
\text { Entrevista 2 }\end{array}$ \\
\hline $\mathrm{N}+1$ & $\begin{array}{l}\text { Recursos utilizados pelo professor para o } \\
\text { projeto de aula sobre Volume de Sólidos } \\
\text { Geométricos. }\end{array}$ & Entrevista 3 \\
\hline
\end{tabular}

Fonte: Os autores (2018)

Conforme Rocha e Trouche (2015), ao analisarmos a trajetória documental (Quadro 1), investigamos os eventos que são os motores do trabalho documental. Este instrumento trata-se de um modelo que relata a história dos professores com os recursos por meio da análise dos eventos que propiciam a sua elaboração de documentos.

Para compreender essa trajetória, nós observamos o passado e investigamos quais e como os eventos importantes afetaram o sistema de recursos e o sistema documental dos professores. Esses sistemas não são estáticos e estão sempre em evolução, pois são suscetíveis de serem afetados por diversas situações que os professores vivenciam dentro e fora da sala de aula (ROCHA; TROUCHE, 2015, 17).

Sobre a RESR (Quadro 1), essa consiste em pedir a um professor que represente em papel e lápis, a estrutura dos recursos organizados para sua atividade de ensino. Segundo Gueudet e Trouche (2008, p.3), trata-se de uma representação em duplo sentido:

Uma representação externa, uma esquematização, que poderá ser explorada pelo pesquisador, que busca desta inferir os elementos da estrutura do sistema de documentos do professor;

Uma representação interna, no sentido que ela demonstra o modo pelo qual o professor se representa, e deseja apresentar aquele que o interroga, os elementos da organização de seu trabalho.

Nos registros do jornal de bordo, devemos primar para que os recursos utilizados e os suportes produzidos apresentem uma estreita relação. A explicitação das fontes dos recursos (referência dos livros, endereços dos sites, etc.) se faz importante. Os suportes 
Elisângela Bastos de Mélo Espíndola, Jairo José Ribeiro Toscano de Brito Júnior e Rayssa de Moraes da Silva

Recursos para o Ensino de Volume em Níveis de Atividade do Professor de Matemática

produzidos se configuram, por exemplo, como: anotações sobre as escolhas de atividades, ficha de exercícios, entre outras.

Quanto às entrevistas, no nosso caso, utilizamos esse instrumento para o estudo dos recursos do professor em cada um dos níveis: nível +3 - valores e concepções sobre o ensino e a aprendizagem/ em matemática; nível +2 - construção do tema e nível +1 projeto de aula. A fim de melhor compreendermos a composição do sistema de recursos do professor e seu trabalho documental.

\section{Nível +3 - Concepções sobre o ensino e a aprendizagem /em matemática}

No nível +3 , buscamos identificar os recursos do professor relacionados à sua concepção sobre o ensino e a aprendizagem/em matemática. Para tanto, utilizamos a trajetória documental (Figura 1). Por meio desse instrumento tivemos acesso aos eventos e recursos marcantes na vida profissional do professor - no período de 2011 a 2018. Ou seja, de seu ingresso na Licenciatura em Matemática (LM) até o momento da realização da pesquisa, onde se encontrava atuando como docente na rede pública estadual de Pernambuco.

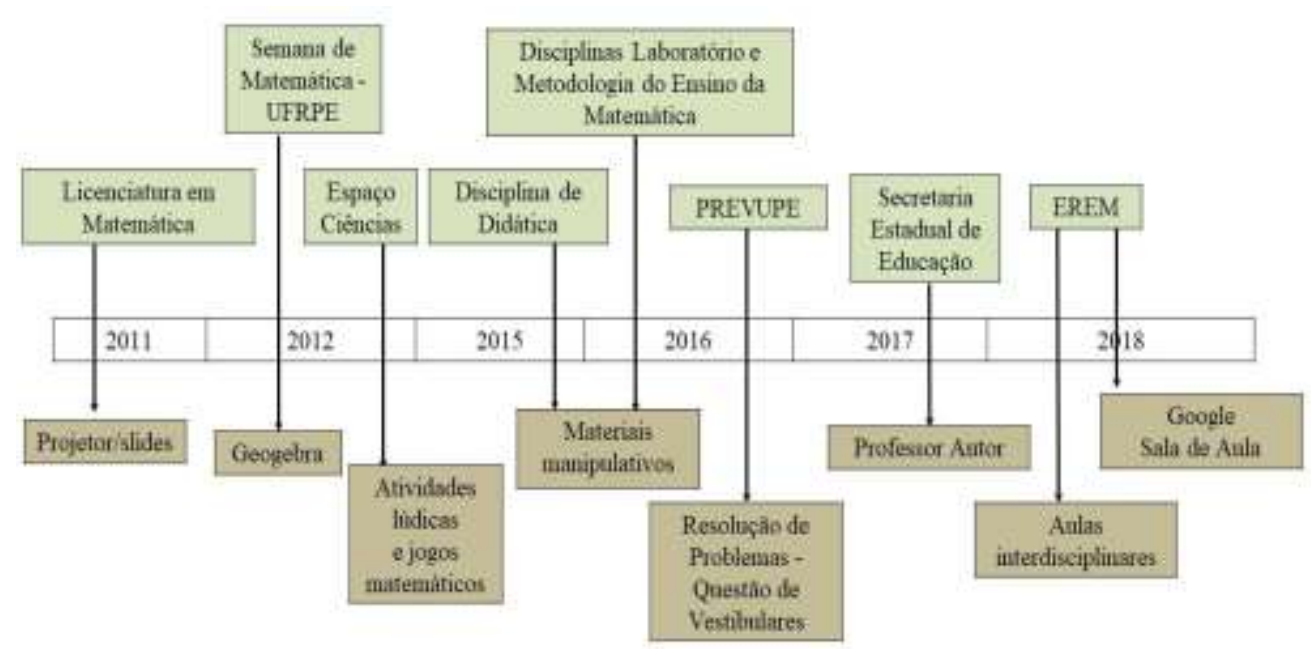

Figura 1 - Trajetória documental (nível +3)

Fonte: Os autores (2018).

Na Figura 1, percebe-se que há uma relação entre o ingresso do professor na LM e o uso dos recursos "projetor/ slides". Quando universitário ele observou que grande parte dos seus professores utilizava tais recursos. Isso, em sua opinião, tinha um resultado positivo, na medida em que "prendia a atenção dos alunos". Esse evento, fez 
Elisângela Bastos de Mélo Espíndola, Jairo José Ribeiro Toscano de Brito Júnior e Rayssa de Moraes da Silva

Recursos para o Ensino de Volume em Níveis de Atividade do Professor de Matemática

com que ele gostasse de organizar suas aulas em slides, devido à praticidade e facilidade em dispor o conteúdo, de uma forma visual, mais agradável aos alunos.

Ainda na LM, por meio das disciplinas de Didática, Laboratório e Metodologia do Ensino da Matemática, ele pôde desenvolver a utilização de materiais manipulativos/concretos. Ao participar de um minicurso - "O uso do GeoGebra no ensino de Geometria”, oferecido na Semana de Matemática - UFRPE, ele desenvolveu habilidades no uso do GeoGebra. Desde então, o uso do GeoGebra é um dos seus preferidos para trabalhar o eixo de Álgebra e elaborar suas aulas sobre Funções.

Outro evento que marcou a trajetória documental do professor (Figura 1) foi sua experiência como "mestre docente" no Pré-vestibular da Universidade de Pernambuco (PREVUPE). Onde aprofundou seus conhecimentos sobre "questões de vestibulares de diversas universidades". Quando estagiou no Espaço Ciência, ele desenvolveu habilidades em criar jogos matemáticos, além de utilizar aqueles já existentes no laboratório de matemática desta instituição - previstos para serem socializados em oficinas com alunos e/ou professores.

Em sua vivência, como professor na Rede Estadual de Ensino - PE, ele destacou o acesso a "aulas prontas em slides", disponíveis na internet, no site da Secretaria Estadual de Educação, na sessão "Professor Autor" ${ }^{4}$. Sendo possível adaptá-las quando necessário para atender melhor às necessidades de suas turmas.

Sua atuação na EREM levou-o a trabalhar com aulas interdisciplinares, desenvolvidas no trabalho coletivo entre professores e coordenação da escola. Bem como, a troca de experiências com os colegas da referida escola, levou-o a conhecer a ferramenta Google Sala de Aula (Google Classroom). De acordo com o professor, esse aplicativo trata-se de uma sala de aula virtual; onde um administrador cria uma "turma" e logo em seguida é gerado um código para acessá-la. Por meio desse recurso, ele tem compartilhado com alunos de diferentes turmas, as atividades realizadas e previstas para o estudo dos temas matemáticos. A título de exemplo, da turma em tela, como veremos a seguir, na análise dos recursos do professor nos próximos níveis.

\section{Nível +2 - Construção do tema Volume de Sólidos Geométricos}

\footnotetext{
${ }^{4}$ Disponível em: https://www1.educacao.pe.gov.br/cpar/
} 
Elisângela Bastos de Mélo Espíndola, Jairo José Ribeiro Toscano de Brito Júnior e Rayssa de Moraes da Silva

Recursos para o Ensino de Volume em Níveis de Atividade do Professor de Matemática

Na Figura 2 pode ser vista a RESS apresentada pelo professor para o nível +2 construção do tema Volume de Sólidos Geométricos:

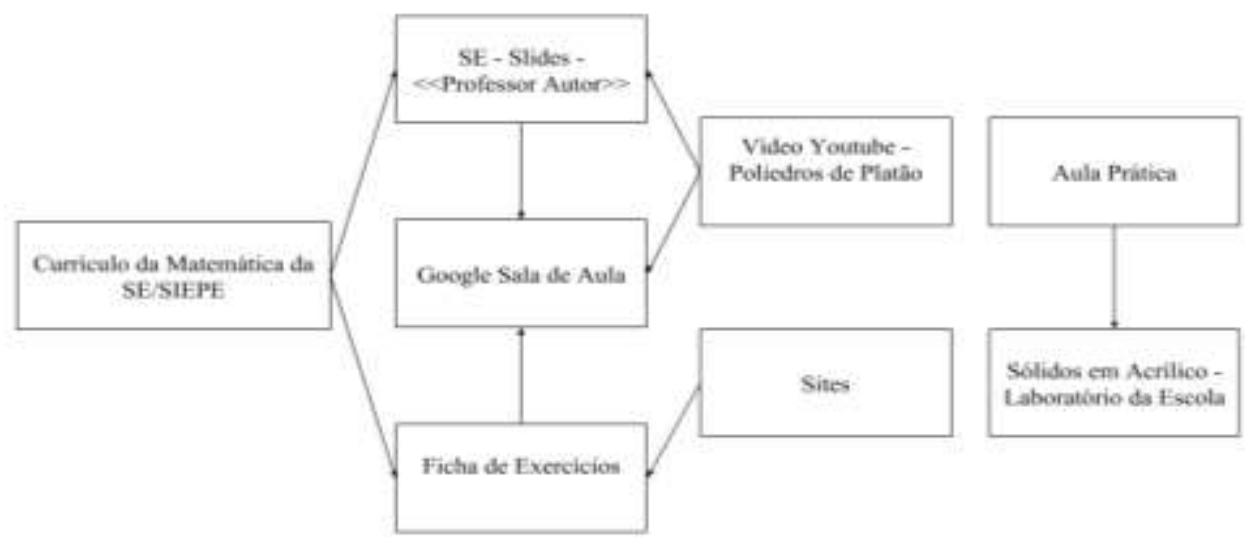

Figura 2 - RSSR nível +2

Fonte: Os autores (2018).

O professor utilizou o currículo da Rede Estadual de Ensino- PE (Figura 2), no que concerne às orientações sobre o ensino do Eixo Grandezas e Medidas.

\begin{tabular}{|c|c|c|}
\hline \multicolumn{3}{|c|}{$2^{\circ}$ ANO DO ENSINO MEDID $\left(11^{\circ}\right.$ ANO) } \\
\hline CAMPOS OU EIKOS & GoNitioos & EXPECTATINAS OE APAENOCZAGEM - 2 BMESTHE \\
\hline $\begin{array}{l}\text { GRANDEZAS E } \\
\text { MEDIDAS }\end{array}$ & 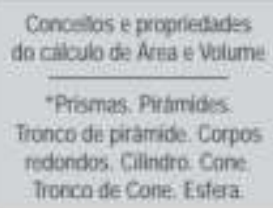 & 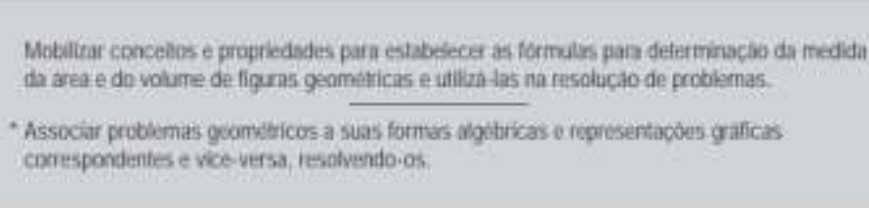 \\
\hline
\end{tabular}

Figura 3 - Extrato do currículo da Secretaria Estadual de Educação de Pernambuco Fonte: http://www.educacao.pe.gov.br

O Google Sala de Aula (Figura 2) foi utilizado pelo professor para disponibilizar aos alunos do $2^{\circ}$ ano do EM: slides, listas de exercícios e assuntos da prova. Conforme afirmação do professor: "o Google Sala de Aula funciona como uma extensão da classe, uma vez que as atividades permanecem disponíveis aos alunos, mesmo depois que se encerram as aulas na escola".

Os slides utilizados pelo professor foram àqueles disponíveis no site da Secretaria Estadual de Educação no Espaço Concurso Professor-Autor ${ }^{5}$. Isto é: vinte e oito slides, dos quais ele chegou a utilizar vinte e um deles, contendo apresentações sobre: a presença dos sólidos geométricos em vários contextos do dia a dia, nos objetos, nas construções, na natureza, etc.; classificação dos sólidos geométricos (poliedros e

${ }^{5}$ Fonte: https://www1.educacao.pe.gov.br/cpar/ 
Elisângela Bastos de Mélo Espíndola, Jairo José Ribeiro Toscano de Brito Júnior e Rayssa de Moraes da Silva

Recursos para o Ensino de Volume em Níveis de Atividade do Professor de Matemática

não poliedros); elementos de um poliedro, classificação dos poliedros; planificação de poliedros, relação de Euler e exercícios para o cálculo do volume do cubo, bloco retangular e prismas.

Em um dos slides do recurso Espaço Concurso Professor-Autor, havia a indicação de um vídeo do YouTube - Sólidos de Platão ${ }^{6}$, que também foi utilizado pelo professor. Na Figura 2, também foi indicado, o uso do kit em acrílico de sólidos geométricos (disponível na escola), embora não tenha sido empregado nas aulas da turma do $2^{\circ}$ ano do EM que observamos.

\section{Nível +1 - Projeto de aula}

Em particular, o trabalho documental do professor em relação à preparação da aula sobre Volume de Sólidos Geométricos (nível +1) foi baseado em uma apostila sobre Áreas e Volumes da Faculdade Assis Gurgacz (MISIAK, 2009), disponível na internet. Consideramos que a referida apostila configurou-se como um recurso-mãe no trabalho documental do professor. Visto que dos quarenta exercícios contidos nessa apostila, o professor selecionou quinze exercícios, realizando sobre esses algumas modificações - construindo assim, uma nova ficha de exercícios (um recurso- filho).

Especificamente, sobre o projeto de aula em tela (nível +1), o professor selecionou quatro dos quinze exercícios contidos na ficha que ele elaborou (recursofilho). No Quadro 2, podemos perceber algumas modificações realizadas nos exercícios selecionados (destacadas em negrito).

Quadro 2 - Modificações nos exercícios realizadas pelo professor (nível +1).

\begin{tabular}{|l|l|}
\hline \multicolumn{1}{|c|}{ Recurso - mãe } & \multicolumn{1}{|c|}{ Recurso - filho } \\
\hline $\begin{array}{l}\text { 1. Num paralelepípedo, as dimensões da } \\
\text { base são } 4 \mathrm{~cm} \text { e } 7 \mathrm{~cm} \text {. Sendo a altura do } \\
\text { paralelepípedo } 5 \mathrm{~cm} \text {, determine o } \\
\begin{array}{l}\text { volume. Quanto material será usado } \\
\text { para construir esta caixa? }\end{array}\end{array}$ & $\begin{array}{l}\text { paralelepípedo cujas dimensões da base são } \\
\text { paralelepípedo } 5 \mathrm{~cm} \text {, determine: } \\
\text { a) O volume da caixa. } \\
\text { b) Se desejarmos revestir esta caixa com } \\
\text { papel decorativo, quantos metros } \\
\text { quadrados de papel serão necessários? }\end{array}$ \\
\hline
\end{tabular}

${ }^{6}$ Fonte: https://www.youtube.com/watch?v=AOG8t_rPSKQ 
Elisângela Bastos de Mélo Espíndola, Jairo José Ribeiro Toscano de Brito Júnior e Rayssa de Moraes da Silva

Recursos para o Ensino de Volume em Níveis de Atividade do Professor de Matemática

2. Quantos litros de água são necessários para encher uma caixa d água cujas dimensões são: $1,20 \mathrm{~m}$ por $90 \mathrm{~cm}$ por $1 \mathrm{~m}$ ? (lembre-se que $1 \mathrm{~m}^{3}$ $=1000$ litros).

3. Um cubo tem área de $96 \mathrm{~m}^{2}$. Qual é a medida da aresta do cubo? Determine seu volume:

4. Quantos $\mathrm{cm}^{2}$ de papel adesivo são gasto para cobrir a superfície total de uma peça sextavada cuja forma e medidas estão na figura abaixo? Qual o volume da peça?

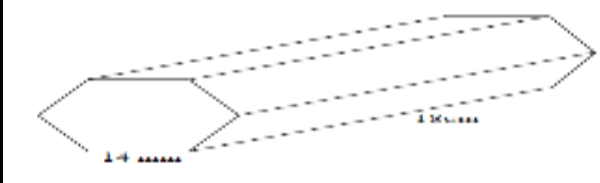

2. Quantos litros de água são necessários para encher uma caixa d’água cujas dimensões são: $1,20 \mathrm{~m}$ por $90 \mathrm{~cm}$ por $1 \mathrm{~m}$ ? (lembre-se que $1 \mathrm{~m}^{3}=1000$ litros).

3. Um cubo tem área de $96 \mathbf{c m}^{2}$. Qual é a medida da aresta do cubo? Determine seu volume:

4. Quantos $\mathrm{cm}^{2}$ de papel adesivo são gasto para cobrir a superfície total de uma peça em forma de prisma, cuja base é um hexágono regular? Qual o volume da peça?

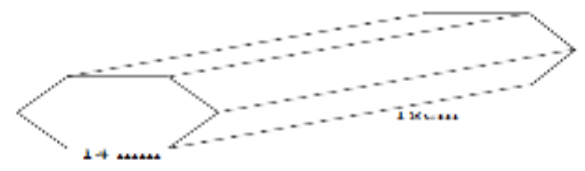

Fonte: Os autores (2018).

No Quadro 2, percebe-se que as modificações dos exercícios, ancorou-se nos conhecimentos propostos por Comiti, Grenier e Margolinas (1995) referentes ao nível +1 . No presente caso, sobre os conhecimentos e as dificuldades habituais dos alunos a propósito de Volume de Sólidos Geométricos. Dessa forma, no primeiro exercício o professor acrescentou um novo objeto: a caixa de madeira. Segundo ele, esse acréscimo teve a intenção de caracterizar o paralelepípedo, para assim facilitar a percepção dos alunos em relação ao sólido geométrico em questão. Também no primeiro exercício, o professor optou por alterar a estrutura do enunciado original, apresentando-o em dois itens distintos ( $\mathrm{a}$ e $\mathrm{b}$ ).

No segundo exercício, não constatamos alterações. No entanto, no terceiro exercício (Quadro 2) ocorreu alteração quanto à unidade de medida da área da face do cubo (de $\mathrm{m}^{2}$ para $\mathrm{cm}^{2}$ ). Conforme o professor, como uma tentativa de facilitar a visualização do objeto, por ser mais simples idealizar um cubo com as arestas em centímetros do que em metro.

Sobre o quarto exercício (Quadro 2), a modificação realizada foi a substituição do termo "uma peça sextavada" por "uma peça em forma de prisma, cuja base é um hexágono regular". Embora, o exercício apresentasse a figura da peça, o professor fez 
Elisângela Bastos de Mélo Espíndola, Jairo José Ribeiro Toscano de Brito Júnior e Rayssa de Moraes da Silva

Recursos para o Ensino de Volume em Níveis de Atividade do Professor de Matemática

essa alteração por acreditar que os alunos não relacionariam o termo "sextavada" à base hexagonal.

Como análise prévia das possíveis dificuldades dos alunos ( nível 0), o professor chegou a mencionar que eles poderiam não conseguir calcular corretamente a área da base, sobretudo do quarto exercício. E, por conseqüência, errariam o cálculo do volume do sólido. De outra forma, eles poderiam apresentar dificuldades com relação ao cálculo das áreas laterais dos prismas, em virtude de não reconhecerem as medidas das arestas, para calcular as áreas das faces e estabelecer a relação entre elas e enfim, determinar a área total dos prismas.

Grosso modo, consideramos que as escolhas dos exercícios e modificações realizadas no projeto da aula (nível +1) põe em evidência como esse se articula com os demais níveis de atividade do professor. Dentre outros exemplos possíveis, destacamos no nível +3 - os tipos de exercícios escolhidos pelo professor à luz de seus conhecimentos sobre a noção matemática e a aprendizagem por meio da "resolução de problemas”. Não obstante do nível +2 , sobre os conhecimentos relativos à situação de ensino/aprendizagem - fato observado, na socialização dos exercícios por meio do recurso Google Sala de Aula, como forma de assegurar aos alunos (via uso pessoal do celular) - o acompanhamento de todas as atividades realizadas e previstas sobre o estudo do tema.

\section{Considerações finais}

O objetivo deste trabalho foi identificar o sistema de recursos de um professor de matemática nos níveis de sua atividade e na sua relação com o ensino de Volume de Sólidos Geométricos. Ao desenvolvermos esse estudo, no estágio supervisionado obrigatório, isso nos possibilitou conhecer novos recursos, a exemplo do Google Sala de Aula, slide do Espaço Concurso Professor-Autor da Secretaria de Educação de PE, dentre outros.

Cremos que os resultados sobre os recursos do professor nos diferentes níveis de sua atividade podem nos levar a melhor compreender suas escolhas didáticas. Por exemplo, quando o professor escolheu um recurso (ficha de exercícios da internet) para ser usado em uma aula sobre Volume de Sólidos Geométricos, isso se inseriu em uma concepção mais ampla sobre o ensino e a aprendizagem da matemática (nível +3 ), fruto 
Elisângela Bastos de Mélo Espíndola, Jairo José Ribeiro Toscano de Brito Júnior e Rayssa de Moraes da Silva

Recursos para o Ensino de Volume em Níveis de Atividade do Professor de Matemática

de sua trajetória documental; ou seja, de suas experiências profissionais em termos de eventos e acesso a diferentes tipos de recursos.

Também é possível perceber uma relação entre os recursos do nível +2 no projeto de aula (nível +1 ), quanto ao uso de uma ficha de exercício da internet e não do livro didático - ausente em sua RSSS (Figura 2). Bem como o uso do Google Sala de Aula. O que denota certa preferência do professor por recursos relacionados à tecnologias digitais.

Embora não tenhamos tratado nesse artigo, uma análise do trabalho documental sobre os quinze exercícios trabalhados na construção do tema (nível +2); consideramos que as modificações realizadas pelo professor do recurso-mãe ao recurso-filho acerca das alterações nos exercícios (Quadro 2) - referentes ao projeto de aula (nível +1) apontam indícios como esses se ancoram em conhecimentos profissionais docentes. $\mathrm{O}$ que nos faz crer que novas pesquisas sobre os recursos dos/para os professores na preparação e na implementação de suas aulas em classe podem contribuir, significativamente, a novas reflexões acerca da formação inicial e continuada para docência em matemática.

\section{Referências}

COMITI, C.; GRENIER, D.; MARGOLINAS, C. Niveaux de connaissances en jeu lors d'interactions en situation de classe et modélisation de phénomènes didactiques.In: ARSAC, G.; GRÉA, J.: GRENIER, D.; TIBERGHIEN, A. Différents types de savoirs et leur articulation. Grenoble: La Pensée Sauvage, 1995, p.92-113. Disponível em: https://hal.archives-ouvertes.fr. Acesso em: 09 out.2018.7

GUEUDET, G.; TROUCHE, L. Des ressources aux documents, travail d'enseignant et genèses documentaires. In: GUEUDET, G.; TROUCHE, L. (Eds.). Ressources vives: le travail documentaire des professeurs en mathématiques. Rennes: Presses Universitaires de Rennes, 2010. p. 57-74.

GUEUDET, G.; TROUCHE, L. Méthodologie: comment suivre et analyser les genèses documentaires des enseignants? Lyon: Ifé, 2008. Disponível em: <http://educmath.enslyon.fr/Educmath/recherche/approche_documentaire/methodologie>. Acesso em: 16 set. 2018.

GUEUDET, G.; TROUCHE, L. Vers de nouveaux systèmes documentaires pour les enseignants de mathématiques? In: BLOCH; CONNE, F. Actes de la XIVe école d'été de didactique des mathématiques. Saint- Livrade: Pensée Sauvage, 2007. p. 109-133. 
Elisângela Bastos de Mélo Espíndola, Jairo José Ribeiro Toscano de Brito Júnior e Rayssa de Moraes da Silva

Recursos para o Ensino de Volume em Níveis de Atividade do Professor de Matemática

HAMMOUD, R. Le travail collectif des professeurs en chimie comme levier para la mise en œuvre de démarches d'investigation et le développement des connaissances professionnelles: contribution au développement de l'approche documentaire du didactique. 2012. 389f. Thése de doutorat. Sciences de l'Education. Université Claude Bernard - Lyon I; Université Libanaise, 2012.

LIMA, I; TRGALOVA, J. Connaissances des professeurs susceptibles d'influencer leurs décisions didactiques. SIMPÓSIO INTERNACIONAL DE PESQUISA EM EDUCAÇÃO MATEMÁTICA, 2., 2008, Recife. Anais... Recife: UFRPE, 2008. p. 112.

MARGOLINAS, C. La situation du professeur et les connaissances en jeu au cours de l'activité mathématique en classe. In: SIMMT, E.; DAVIS, B. (ed.), Actes 2004 de la rencontre annuelle du groupe canadien d'étude en didática des mathématiques, Edmonton: CMESG/GCEDM, 2005. p.3-21.

MARGOLINAS, C. Situations, milieux, connaissances. Analyse de l'activité du professeur. In: DORIER, J.-L. et al. (Eds.). Actes de la 11e École d'Été de Didactique des Mathématiques. Grenoble: La Pensée Sauvage, 2002. p. 141-156.

MARGOLINAS, C.; WOZNIAK, F. Rôle de la documentation scolaire dans la situation du professeur: le cas de l'enseignement des mathématiques à l'école élémentaire. In: GUEUDET, G.; TROUCHE, L. (Eds.). Ressources vives: le travail documentaire des professeurs en mathématiques. Rennes: Presses Universitaires de Rennes, 2010. p.223269.

MISIAK, A. S. F. Áreas e Volumes, Conjuntos Numéricos: Engenharia. Cascavel: Faculdade Assis Gurgacz, 2009. Disponível em: <Fonte:https://www.google.com/url?sa=t\&rct=j\&q=\&esrc=s\&source= web\&cd=10\&ved=2ahUKEwiK_aCAu9vcAhWBI5AKHTLUDHEQFjAJegQIABAC\& url=https $\% 3 \mathrm{~A} \% 2 \mathrm{~F} \% 2 \mathrm{Falexfisica}$.files.wordpress.com\%2F $2011 \% 2 \mathrm{~F} 12 \% 2 \mathrm{Fexercicios}-$ de-volume-nono-ano.doc\&usg=AOvVaw0KGMtQtjO-ndeBgf-S8rGu>. Acesso em: 28 out. 2018 .

ROCHA, K.; TROUCHE, L. Da produção coletiva de livros didáticos digitais aos usos feitos por professores de matemática: o caso do grupo francês sésamath. Em Teia, Recife, v.6, n.3, p. 1-22, 2015.

SABRA, H. L'étude des rapports entre documentations individuelle et collective: incidents, connaissances et ressources mathématiques. Recherches en Didactiques des Mathématiques, Paris, v.36, n.1, p.49-95, 2016.

TROUCHE, L. Compreender o trabalho do professor com os recursos de seu ensino, um questionamento didático e informático.In: SIMPÓSIO LATINO-AMERICANO DE DIDÁTICA DA MATEMÁTICA, 1., 2016, Bonito. Anais... Bonito: UFMG, 2016. p. $1-32$. 